\title{
Convenções financeiras e a taxa básica de juros no Brasil: uma primeira aproximação
}

\section{LUCIANA SEABRA DAVID DEQUECH*}

Financial conventions and basic interest rate in Brazil. This article discusses the thesis that the Brazilian interest rate is a convention, focusing on the basic interest rate under the inflation targeting regime. On the one hand, there are some complications involved in this debate. In order to show this, we consider the theoretical works that have been references for the Brazilian economists who see an interest rate convention in the country. On the other hand, despite the difficulties, it is possible to find signs of conventionality in the determination of the Brazilian basic rate, by analyzing two properties of conventions: conformity of some with the conformity of others; and arbitrariness.

Keywords: convenções; Keynes; taxa de juros; metas de inflação.

JEL Classification: B52; E43; E58.

Este artigo pretende contribuir para o debate a respeito das taxas de juros no Brasil, concentrando-se sobre a tese de que a taxa de juros brasileira é formada com base em uma convenção. Tal tese pode ser intencionalmente apresentada desta forma genérica, mas, dado que existem várias taxas de juros, insistiremos sobre a necessidade de identificar a qual taxa ou a quais taxas se aplicaria a tese da convenção de juros. Nossa análise sobre a experiência brasileira trata especificamente da possível convencionalidade da taxa básica de juros no país e restringe-se ao

\footnotetext{
* Luciana Seabra é jornalista do jornal Valor Econômico. E--mail: Luciana.seabra@valor.com.br; David Dequech é professor do Instituto de Economia da Universidade Estadual de Campinas - Unicamp. E-mail: dequech@eco.unicamp.br. Este artigo é baseado em parte da dissertação de mestrado de Seabra, orientada por Dequech. Os autores são gratos a dois pareceristas, por seus comentários e sugestões, eximindo-os de responsabilidade por quaisquer erros ou omissões. Seabra agradece ao CNPq a bolsa de mestrado e Dequech a bolsa de produtividade em pesquisa. Submetido: 16/setembro/2011; Aprovado: 16/janeiro/2013.
} 
período que começa com a implementação do regime de metas de inflação, em 1999. ${ }^{1}$ Ao mesmo tempo, vários argumentos mais gerais sobre convenções em mercados financeiros e relativas à taxa básica de juros também serão apresentados.

Entre os primeiros autores a usar a ideia de convenção para tratar das taxas de juros no Brasil nos anos recentes estão Bresser-Pereira e Nakano (2002b): “[d] epois da persistente manutenção da taxa de juros em nível muito elevado, é natural que surja o medo de redução e que esse nível se torne uma convenção, no sentido keynesiano do termo, e também uma armadilha. Não será, portanto, fácil, escaparmos do equilíbrio perverso da taxa de juros em que nos metemos há muitos anos” (também 2002a: 169 e Bresser-Pereira, 2003, p. 389).

Outro autor a mencionar é Modenesi, que afirma, ao tratar do período 2000-2007: "a evidência empírica corrobora a tese de que a formação da taxa de juros no país vem-se fundamentando em uma convenção (Keynes, 1937) pró-conservadorismo na condução da política monetária” (2008, p. 2).

Também Chernavsky (2007), em uma análise dos juros reais praticados no Brasil a partir de 1993, sustenta que as explicações comumente sugeridas pela abordagem teórica ortodoxa são insuficientes para justificar os patamares das taxas, que ele considera extremamente elevados. Para explicá-los, Chernavsky faz referência às análises de André Orléan, em parte baseadas em Keynes. Orléan é um dos pais fundadores da chamada économie des conventions, uma das principais correntes heterodoxas de pensamento econômico na França. Chernavsky também sugere que as taxas de juros "no sistema de metas de inflação em geral, e no caso do Brasil em particular, não resultam de equilíbrio alcançado por uma série de variáveis econômicas fundamentais, mas são explicadas a partir das convenções específicas adotadas pelo conjunto de agentes relevantes acerca das taxas necessárias para que suas expectativas de inflação permaneçam próximas às metas" (2008, p. 1).

Não fazia parte das intenções desses autores deter-se sobre o conceito de convenção e sobre as abordagens de Keynes e Orléan às convenções financeiras, mas sim ressaltar aspectos empíricos ou aplicados ao Brasil. Em contraste, Erber (2011, 2012), que também se refere às taxas de juros brasileiras e cita Orléan e outros convencionalistas franceses, estende-se bastante sobre o conceito de convenção. Por outro lado, ele usa a noção de convenção de desenvolvimento, algo mais amplo do que uma convenção de juros altos. A contribuição de Erber será objeto de uma discussão à parte, nem outro texto, por causa do foco do presente artigo na taxa de juros e das restrições de espaço, comparadas à extensão e à complexidade dos comentários de Erber sobre o conceito de convenção de desenvolvimento.

O primeiro objetivo deste artigo é contribuir para aprofundar o debate dos aspectos conceituais e teóricos da tese da convencionalidade da taxa de juros, comentando as abordagens de Keynes e dos convencionalistas, que servem de refe-

\footnotetext{
${ }^{1}$ Presumivelmente, afirmar a tese da convencionalidade da taxa básica de juros seria ainda mais complicado em se tratando do período precedente, com um regime de câmbio fixo, sob o qual a autoridade monetária tem menos graus de liberdade quanto a aspectos importantes.
} 
rência aos economistas brasileiros mencionados anteriormente, e propondo a adoção de um conceito ao mesmo tempo amplo e específico de convenção. Como as citações feitas acima já indicam, esses autores têm remetido às ideias de Keynes sobre convenção. Keynes (1936, p. 203) de fato afirma que a taxa de juros é um fenômeno altamente convencional. Deve-se notar, entretanto, que a taxa de juros que Keynes descreve assim na Teoria Geral é a taxa de juros de mercado de longo prazo. Além disso, ao afirmar tal convencionalidade, Keynes adota algumas hipóteses que podem restringir o escopo de sua análise, como discutiremos adiante. Ainda com relação a Keynes, deve-se notar que ele só tratou com detalhe de uma convenção no mercado de ações e não no mercado de títulos de dívida e, mais ainda, o mercado de ações tem importantes especificidades. É também sobre o preço das ações e não sobre a taxa de juros que se debruça Orléan, a quem alguns dos autores brasileiros citados acima se referem, quando ele trata de convenções financeiras. ${ }^{2}$ É preciso considerar as especificidades de cada mercado financeiro ou situação ao tentar estender análises sobre convenções na bolsa de valores ao mercado de títulos e, portanto, à determinação das taxas de juros. Outras questões que podem ser levantadas diante do debate sobre uma convenção de juros altos no Brasil dizem respeito ao conceito de convenção: qual é o conceito adotado e exatamente em que sentido(s) a taxa de juros no Brasil seria convencional?

O segundo objetivo do artigo é, com base no conceito de convenção a ser defendido logo adiante e em perspectiva teórica que pode ser classificada genericamente como institucionalista, ajudar a identificar sinais de convencionalidade também na taxa básica de juros, para o caso brasileiro, ou ao menos dar pistas sobre onde outros sinais poderiam ser encontrados.

Não pretendemos responder por que a taxa básica de juros brasileira ou a diferença entre ela e a observada em muitos outros países tem sido tão alta durante a vigência do regime de metas de inflação. $\mathrm{O}$ artigo fornece elementos que podem ser aproveitados em uma discussão sobre isso, em particular no que se refere à possível convencionalidade da taxa básica, mas não considera outros aspectos importantes do debate sobre o alto patamar em que tem ficado essa taxa, como aqueles referentes à política macroeconômica mais ampla, incluindo as políticas cambial e fiscal e o grau de abertura da economia. Alguns pontos que também aparecem nesse debate mais amplo surgem aqui apenas na medida em que forem relacionados com a tese da convencionalidade da taxa básica.

Os conceitos de convenção, apesar de manterem uma base comum, são bastante variados, de modo que devemos ser tão explícitos e específicos quanto possível sobre este termo ao aplicá-lo à determinação da taxa básica de juros no Brasil. As referências a Keynes, em particular, não resolvem completamente este problema, já que ele não definiu explicitamente o que chamou de convenção embora seja possível encontrar implícitos em sua obra os aspectos principais do

\footnotetext{
${ }^{2}$ Orléan estuda também outros contextos em que aplica a ideia de convenção, além dos mercados financeiros.
} 
conceito adotado aqui - e deu margem a várias interpretações diferentes (Dequech, 2011). Para argumentar de forma mais organizada e precisa sobre a possível existência de convenções na definição da taxa básica de juros brasileira, vamos recorrer explicitamente a um conceito amplo, mas razoavelmente detalhado. Segundo Dequech (2009, p. 73 e 2011, p. 482), uma convenção é uma instituição (um sistema socialmente compartilhado de regras de comportamento e/ou de pensamento) com pelo menos duas características: “(1) the property that I call conformity with (expected) conformity, which means that a convention, when followed consciously, is followed at least in part because others (are expected to) follow it; and (2) arbitrariness, in the sense that an alternative that is not clearly inferior to the prevailing pattern is conceivable".

O restante do artigo está organizado da seguinte maneira. A primeira seção faz uma descrição e discussão das abordagens de Keynes e dos convencionalistas, de modo bastante breve (em função dos limites de espaço), apenas o suficiente para mostrar que não é imediata a aplicação das ideias desses autores à determinação das taxas de juros e em particular da taxa básica no Brasil. A segunda seção mostra, com base no conceito proposto por Dequech e em ideias teóricas adicionais, alguns aspectos convencionais na determinação da taxa básica de juros no Brasil, durante o período do regime de metas de inflação. A terceira conclui o artigo.

\section{KEYNES E OS CONVENCIONALISTAS SOBRE CONVENÇÕES FINANCEIRAS: BREVES COMENTÁRIOS}

As contribuições de Keynes e dos convencionalistas ao estudo de convenções financeiras exigem uma discussão muito mais extensa do que podemos fazer aqui. Ficaremos restritos a uma descrição sumária dos aspectos mais pertinentes aos nossos propósitos, em particular para mostrar que, no debate sobre uma convenção de juros no Brasil, é preciso aprofundar as referências a essas contribuições e constatar que elas não podem ser aplicadas sem mediações e adaptações ao caso da taxa básica de juros, em geral e no Brasil em particular.

\section{Keynes sobre convenções financeiras}

\section{(a) O preço das ações}

Keynes implicitamente entendia uma convenção como uma construção mental, embora tenha se referido também a um comportamento convencional. Ao lidar com a bolsa de valores, Keynes argumenta que as expectativas neste mercado são assim formadas: "[i]n practice we have tacitly agreed, as a rule, to fall back on what is, in truth, a convention. The essence of this convention [...] lies in assuming that the existing state of affairs will continue indefinitely, except in so far as we have specific reasons to expect a change" (1936, p. 152, ênfase original). Esta convenção projetiva deve ser interpretada como um exemplo de convenção para Keynes. $\mathrm{O}$ que está sendo projetado para o futuro neste caso são os preços correntes das ações. 
Outra passagem da Teoria Geral que nos remete à ideia de convenção é a célebre comparação da bolsa de valores com um concurso de beleza de jornais, em que Keynes se refere a agentes buscando antecipar o que a opinião média dos participantes espera que a opinião média seja no futuro e assim por diante (p. 156). Embora Keynes não use nessa passagem o termo "convenção", é possível conectar a imagem do concurso de beleza a uma das técnicas em que consiste a "teoria prática do futuro" adotada pelos agentes econômicos diante da incerteza, tal como descrita por Keynes (1937) em seu artigo no Quarterly Journal of Economics: "we endeavour to conform with the behaviour of the majority or the average. The psychology of a society of individuals each of whom is endeavouring to copy the others leads to what we may strictly term a conventional judgement" (1937a, p. 214, ênfase original). Há, contudo, uma diferença. Ao tratar do concurso de beleza, Keynes explica a adesão à convenção por uma forma de efeito coordenação. Já a técnica mimética é justificada pelo argumento de uma possível diferença informacional: " $[\mathrm{k}]$ nowing that our own individual judgement is worthless, we endeavour to fall back on the judgement of the rest of the world, which is perhaps better informed" (1937, p. 214).

Mais ainda, a imagem do concurso de beleza parece tratar o mercado de ações como um sistema em que há uma autodeterminação ou determinação endógena: o preço das ações é determinado apenas pela opinião e pelo comportamento de quem age nesse mercado e não com base numa referência externa a ele. Esta é uma especificidade importante do mercado de ações, tal como visto por Keynes, e dá origem a profecias autorrealizáveis.

\section{(b) A taxa de juros}

Keynes afirma na Teoria Geral: "the rate of interest is a highly conventional, rather than a highly psychological, phenomenon. For its actual value is largely governed by the prevailing view as to what its value is expected to be. Any level of interest which is accepted with sufficient conviction as likely to be durable will be durable; subject, of course, in a changing society to fluctuations for all kinds of reasons round the expected normal" (1936, p. 203). Como já mencionado, trata-se aí da taxa de juros - ou uma das taxas - de mercado (inversamente relacionada ao preço dos títulos), assim como ao discutir a bolsa de valores Keynes tratava do preço de mercado das ações.

Aparece claramente aí a ideia de uma profecia autorrealizável, presente também em seu tratamento dos preços das ações. No caso da taxa de juros, no entanto, há algumas complicações para a ideia de um mercado que determinaria endogenamente o valor dessa taxa. Antes de tudo, enquanto no mercado de ações há agentes privados interagindo entre si, no caso do mercado de títulos e da taxa de juros há, adicionalmente, um agente especial e público: o Banco Central. No concurso de beleza keynesiano, os aplicadores na bolsa preocupam-se apenas em antecipar a opinião da maioria; já o Banco Central, ao atuar sobre os juros e os títulos, tem poderes especiais - em particular o de fixar a taxa básica - e objetivos e preocupações próprias. Além disso, é plausível vislumbrar uma série de hipóteses 
restritivas por trás da afirmativa de Keynes de que a taxa de juros de mercado de longo prazo é altamente convencional. Primeiro, Keynes às vezes parece aceitar, na Teoria Geral, a hipótese de oferta exógena de moeda, no sentido de plenamente controlada pelo Banco Central, ou no mínimo não incorpora explicitamente a hipótese de oferta endógena de moeda, não controlada totalmente pelo $\mathrm{BC}$, que manejaria a taxa básica de juros. Segundo, Keynes parece supor que a oferta de moeda é dada. Para Keynes, a taxa de juros de mercado é determinada pela interação entre oferta e demanda de moeda. Assim, dada a oferta de moeda, a taxa de juros seria determinada pela demanda. Terceiro, entre os motivos para desejar liquidez e demandar moeda, Keynes destaca na Teoria Geral (e particularmente no tratamento formal) o motivo especulação. A demanda especulativa por moeda depende de expectativas de variação da taxa de juros, além da confiança nessas expectativas. As expectativas de variação resultam da comparação entre a taxa de juros corrente (ou, a rigor, a mais recentemente observada) e uma taxa considerada "segura" ou "normal" (Keynes, 1936, pp. 201, 203). Em resumo: dada a oferta de moeda, a taxa de juros corrente de mercado de longo prazo é determinada pela demanda especulativa - supondo um papel menos importante ou mais passivo para os demais motivos - e, assim, dada a confiança nas expectativas, pela variação esperada na taxa de juros. Com essas hipóteses, um aumento esperado da taxa de juros implicaria um aumento da demanda especulativa e - dadas as demandas transacional e precaucional por moeda (além do motivo finanças, acrescentado por Keynes após a publicação da Teoria Geral) — um aumento da demanda total por moeda. Isso por sua vez, dada a oferta de moeda, implicaria um aumento da taxa corrente de juros. Assim, mesmo na argumentação de Keynes o valor da taxa de juros corrente na verdade depende em parte de um conjunto de determinantes que ele está supondo como dados. Além disso, é graças a todas essas hipóteses que temos profecias autorrealizáveis neste caso. Aplicar este argumento à determinação da taxa básica de juros requereria abandonar algumas das hipóteses de Keynes na Teoria Geral e examinar como isso poderia afetar o raciocínio. Não é algo imediato. Em particular, Keynes, na Teoria Geral, trata de uma convenção entre os agentes privados sobre a taxa de mercado de longo prazo, e não discute uma convenção compartilhada pelos tomadores de decisão da autoridade monetária quando esses fixam a taxa básica e que papel os agentes privados e suas expectativas desempenham nesse processo.

Podemos interpretar Keynes como implicando um alto grau de convencionalidade não apenas da taxa de juros de longo prazo a cada momento (como explicado acima), mas também da taxa de juros normal de longo prazo. A avaliação de qual é a taxa normal tem bastante de convencional, por dois motivos interligados. Primeiro, essa avaliação é influenciada por uma série de taxas de longo prazo observadas no decorrer de diferentes momentos (como parte da experiência passada que Keynes aponta como um dos determinantes da avaliação da taxa normal, ao lado de expectativas sobre o futuro). Em outras palavras, a avaliação sobre a taxa normal de longo prazo é convencional no sentido de que reflete em parte a série de convenções sobre as taxas correntes de longo prazo. Segundo, já que cada taxa 
corrente de longo prazo depende em parte da opinião da maioria sobre a taxa normal, essa opinião majoritária tende a empurrar a média das taxas de longo prazo correntes (observadas em uma sucessão de vários momentos) rumo ao valor normal estimado pela maioria, dando a esta estimativa um caráter de profecia autorrealizável e levando as pessoas a buscar a opinião da maioria das outras: quando a taxa mais recentemente observada está diferente do valor que a maioria estima como normal, a demanda especulativa de vários agentes fará a taxa corrente se aproximar dessa estimativa, ceteris paribus. Esta cláusula ceteris paribus nos remete de novo à importância das hipóteses por trás da ideia da convencionalidade da taxa corrente, que por sua vez tem, como acabamos de ver, uma interação mútua com a convencionalidade da taxa normal.

Como o próprio Keynes admite na Teoria Geral, o banco central, além de supostamente afetar a oferta (um dos determinantes da taxa corrente de juros de mercado de longo prazo, ao lado da demanda privada), pode também influenciar as expectativas dos agentes privados. Keynes (1936, pp. 202-203) afirma que o banco central pode controlar a taxa de curto prazo e que a avaliação, pelos agentes privados, de qual é a taxa segura ou normal de longo prazo depende não apenas da experiência passada, mas também de expectativas sobre a política monetária futura - até porque, poderíamos acrescentar, a taxa de longo prazo depende de expectativas sobre as taxas futuras de curto prazo.

Ao apontar a convencionalidade da taxa de juros de mercado de longo prazo, Keynes se distancia da teoria neoclássica de que esta taxa seria determinada na esfera "real", pelas forças da produtividade e da frugalidade. E é justamente por ser convencional que esta taxa pode ser afetada pelo banco central (Keynes, 1936, p. 204) e pelas expectativas dos agentes privados, inclusive por suas expectativas sobre a ação futura do banco central.

\section{A abordagem convencionalista aos mercados de ações e de títulos}

\section{(a) Orléan sobre a bolsa de valores}

Vimos que, entre os autores brasileiros citados no início deste artigo, Chernavsky (2007) e Erber $(2011,2012)$ referem-se aos trabalhos de Orléan. Aqui cabe relembrar que Orléan (e.g., 1999) concentra-se sobre a bolsa de valores e que ele a trata, de modo mais forte ou mais explícito do que Keynes, como um sistema autorreferencial, em que a opinião média dos participantes é ao mesmo tempo o objeto e o resultado das expectativas dos agentes. Mais especificamente, a nosso ver, Orléan vai além disso e afirma a determinação endógena dos preços das ações pelos agentes privados que operam nesse mercado, com base em referências internas ao sistema (por contraste com os fundamentals da teoria ortodoxa). Como já apontado, um sistema deste tipo não é facilmente identificado no caso da determinação da taxa de juros de mercado (e, acrescente-se, menos ainda no caso da taxa básica). $\mathrm{O}$ detalhe e o rigor com que Orléan investiga a lógica dos agentes e o funcionamento da bolsa com base nestes princípios ajudam a revelar a especificidade deste mercado e das convenções que aí existem. 
Embora Orléan procure dar mais precisão aos insights de Keynes, mostrando com mais clareza o seu alcance e requisitos, de outro ponto de vista ele se diferencia conceitual e teoricamente de Keynes ao tratar a convenção financeira de modo mais amplo como um modelo qualitativo de avaliação, compatível com diferentes expectativas específicas sobre os preços futuro das ações. Este aspecto da abordagem de Orléan é menos restritivo que a convenção projetiva de Keynes.

\section{(b) Brière sobre o mercado de títulos}

Em grande parte com base na análise teórica de Orléan, outra economista francesa, Marie Brière, estuda os mercados de títulos de dívida. Brière (2005) adota uma perspectiva atual, considerando o papel da autoridade monetária, dos economistas, dos analistas de mercado e dos próprios investidores. Assim como Keynes, ela defende que não há um valor natural para a taxa de juros. A autora busca explicar a coordenação em torno de um valor único e, como Orléan, enxerga a existência de um processo autorreferencial. Dele surgiria uma representação coletiva, referência percebida como comum pelo mercado, que inclui a expectativa sobre variáveis, a relação entre elas e hipóteses sobre o comportamento dos outros agentes, inclusive do Banco Central. Brière afirma que esse conceito é semelhante ao de convenção financeira de Keynes.

A necessidade de coordenação em um ambiente complexo levaria ao surgimento, nos mercados, de listas reduzidas e simplificadas de variáveis a considerar. Brière mostra que essa hierarquização das informações é muito influenciada pelas preocupações dos bancos centrais. Segundo a autora, eles teriam um papel crucial devido não apenas à sua capacidade de influenciar os juros, mas também porque a ampla divulgação dos seus pontos de vista criaria uma saliência em torno da qual o mercado poderia se coordenar. Assim, Brière implica que os bancos centrais influenciam não apenas a seleção de variáveis relevantes, mas também sua interpretação pelos agentes privados.

O trabalho de Brière, ao analisar o mercado de títulos, fornece pistas importantes sobre o tema, mas não é suficiente para nossos propósitos. Em pelo menos alguns aspectos relevantes, o mercado de títulos brasileiro parece ser de fato similar ao tratado pela autora e, por isso, deve se comportar de maneira semelhante. Entretanto, a taxa de juros que Brière afirma resultar de uma representação coletiva é a de mercado, assim como em Keynes. Apesar de enfatizar o papel do Banco Central na criação dessa referência, a autora não trata do processo de formação da taxa básica.

\section{ASPECTOS CONVENCIONAIS DA DETERMINAÇÃO DA TAXA BÁSICA DE JUROS NO BRASIL SOB O REGIME DE METAS DE INFLAÇÃO}

Passemos agora à tese de que há algo convencional na taxa básica de juros brasileira, em particular durante o regime de metas de inflação. Por razões de espaço, não faremos uma caracterização prévia do regime de metas de inflação e da 
política macroeconômica mais ampla, que engloba também a abertura financeira, um nível baixo de controle de capitais e um regime de câmbio consideravelmente flexível, de modo que o diferencial de juros afeta o movimento de capitais e a taxa de câmbio, ajudando a conter a inflação. Buscando uma argumentação que reforce as bases conceituais e teóricas da tese da convencionalidade, agora aplicada ao Brasil, e também ajude a revelar seus alcances e possíveis limites, vamos considerar cada um dos dois aspectos - a conformidade com a conformidade e a arbitrariedade — que, segundo Dequech $(2009,2011)$, caracterizam uma convenção como um tipo específico de instituição. ${ }^{3}$

\section{Conformidade com a conformidade}

Pretendemos discutir aqui se há sistemas de regras de pensamento ou de comportamento socialmente compartilhados que têm influência na determinação da taxa básica de juros no Brasil e que sejam adotados por alguns agentes ao menos em parte porque outros agentes também os adotam (ou porque se espera que irão adotá-los). Com esse propósito, a argumentação será dividida em três subseções, lidando respectivamente com os seguintes aspectos: coordenação e autorrealização; legitimidade; e groupthink. Uma referência teórica útil nessa análise será o trabalho de Dequech (2013) sobre diferentes explicações para a conformidade dos agentes com regras institucionais existentes. Embora sua análise não se restrinja a convenções, várias dessas explicações envolvem o fato de que outros agentes aderem a certo sistema de regras ou se espera que vão aderir.

Exclusivamente para argumentar a favor dessas ideias ou para qualificá-las, faremos referências às análises de alguns autores sobre a taxa básica de juros brasileira. Elas não são as únicas relevantes, nem estão detalhadas aqui.

\section{a) Coordenação e autorrealização}

De acordo com Dequech (2013), uma possível explicação para a conformidade com uma instituição existente envolve a ideia de que em vários casos é do interesse

\footnotetext{
${ }^{3} \mathrm{Um}$ dos pareceristas argumenta, com razão, que as taxas de mercado e a taxa básica são inter-relacionadas e que, por isso, o fato de que as taxas de mercado são sujeitas a convenções poderia fazer com que a taxa básica também seja. Pode-se partir da convencionalidade da taxa de juros de mercado de longo prazo, tomando essa convencionalidade como dada, para chegar à taxa básica e apontar sua convencionalidade também. Ver, por exemplo, o argumento de Modenesi et al. (2013) de que uma especificidade institucional brasileira faz com que a taxa de longo prazo contamine a Selic. Embora não seja por essa linha de raciocínio que iremos prosseguir, ela é compatível com e complementar à nossa argumentação nesta seção, que se concentra mais sobre a própria taxa básica. No presente artigo, já apontamos o fato de que Keynes, ao afirmar que a taxa de longo prazo é uma convenção, não discute a determinação da taxa básica pela autoridade monetária, nem sua possível convencionalidade. Agora vamos argumentar que é possível mostrar sinais de convencionalidade na determinação da própria taxa básica, mesmo antes de se falar da taxa de mercado de longo prazo como convencional. Em etapa posterior, é possível inclusive, partindo deste argumento da convencionalidade da taxa básica, sustentar mais facilmente a tese de que a taxa de longo prazo é convencional, já que essa última em parte depende da taxa básica.
} 
de um agente se coordenar com outros. Na literatura econômica, esse fenômeno aparece sob os rótulos de efeito coordenação, retornos crescentes de adoção etc.

Consideraremos essa questão, em primeiro lugar, a partir da perspectiva do Banco Central e, em seguida, da perspectiva de agentes privados.

Carvalho et al. (2007, p. 194) afirmam que o Banco Central não age "à parte das expectativas e desejos dos bancos". De acordo com os autores, duas razões levariam a autoridade a querer conhecer os pensamentos dos agentes que integram o mercado. A primeira é que a determinação da taxa de juros não pode desconsiderar questões como a solvência dos bancos. Se a liquidez dos bancos for contraída de forma excessiva, a saúde de todo o sistema financeiro pode ser posta em risco. "Em segundo lugar, o Banco Central conduz suas operações também com base na persuasão. Essa persuasão vai funcionar de modo tão mais efetivo quanto menos as ações da autoridade implicarem perdas para os participantes do mercado", explicam.

Carvalho et al. sustentam ainda que, a fim de evitar ocorrências com efeitos desestabilizadores, “o Banco Central procura definir suas ações de política de modo a não frustrar em demasia as expectativas das instituições financeiras quanto à evolução da taxa básica de juros. Esse é o chamado consenso de mercado" (2007, p. 194).

A necessidade de incorporar os padrões de pensamento e comportamento do mercado sobre a inflação e a taxa básica de juros, portanto, parece estar na própria raiz do sistema de metas de inflação, que precisa da transparência e do consenso para se efetivar. Não se trata aqui da mera consideração, pelo Banco Central, de expectativas privadas por elas poderem afetar a taxa de inflação, mas sim de um possível esforço do Banco Central em se coordenar com agentes privados.

Passemos agora à possibilidade de uma busca de coordenação por parte dos próprios agentes privados.

Um dos motivos para isso pode a ser a ocorrência de profecias autorrealizáveis. "In situations where the average opinion is expected to be a self-fulfilling expectation, the more an opinion is expected to gain supporters, the more it tends to really gain supporters and thus to become a representative average opinion and a convention" (Dequech, 2013, p. 90). ${ }^{4}$ Mesmo que as expectativas dos outros ou sua média não sejam conhecidas no momento em que alguém forma suas expectativas, este alguém ainda pode tentar se colocar no lugar dos outros e buscar se conformar ao que espera que sejam no futuro as previsões do grupo.

É possível argumentar que há movimentos de autorrealização em torno da taxa básica de juros, envolvendo diretamente previsões sobre essa taxa ou indiretamente previsões sobre outras variáveis relacionadas.

As expectativas de inflação dos agentes econômicos são peça-chave para a condução da política monetária no regime de metas de inflação. Previsões de um

\footnotetext{
${ }^{4}$ Dequech (2013) explica que a autorrealização das expectativas não tem de estar sempre presente para haver a convencionalidade de um conjunto de ideias. Ele se refere à possível legitimidade ou naturalidade das ideias, de que trataremos adiante.
} 
aumento da inflação podem de fato levar a uma inflação mais alta. Um agente pode estar pessoalmente convencido de que há capacidade instalada para produzir mais e, assim, para atender a um aumento da demanda sem pressão sobre os preços. Diante de manifestações de opiniões alheias diferentes, entretanto, ele pode não se deixar guiar por aquilo que seria sua opinião pessoal isolada. Ao esperar que seus fornecedores, assim como os produtores dos itens que consome, vão aplicar um reajuste sobre os preços, é provável que um produtor faça o mesmo. Algo assim pode passar pela cabeça de diversos agentes. A soma dessas atitudes individuais acabaria efetivamente em inflação. ${ }^{5}$

Pelo mesmo raciocínio, previsões sobre a necessidade de um aumento na taxa básica de juros (ou sobre um patamar alto dessa taxa) para conter a inflação podem fazer com que outros agentes (inclusive no Banco Central) concluam pela necessidade de efetivamente aumentar a taxa básica. Cada agente isolado (inclusive cada membro do Conselho de Política Monetária - Copom) pode achar que não serão necessários juros mais altos, mas ao mesmo tempo acreditar que outros acreditem nisso (e assim sucessivamente).

Um movimento semelhante pode acontecer com as reações dos agentes a anúncios de mudanças na taxa de juros. Mesmo que agentes pensando isoladamente não esperem que isso vá ter maiores impactos sobre o nível de atividade e/ou sobre a inflação, eles podem achar que os outros agentes em conjunto têm uma expectativa diferente e aderir a essa expectativa, a despeito de seu julgamento estritamente individual.

Movimentos de autorrealização também são apontados por Barbosa-Filho (2008) no que se refere ao produto potencial. As modificações da taxa de juros visam a impedir que o crescimento ultrapasse esse potencial, levando ao surgimento de pressões de demanda. A lógica do sistema de metas de inflação é que a taxa de crescimento de longo prazo é determinada por fatores externos ao sistema e tentativas de crescer mais rápido do que os limites determinados pela oferta resultam em aumento da inflação. "The main problem with such a view is that it fails to recognize that the potential output of an economy is an endogenous variable and, therefore, it can and usually is affected by macroeconomic policy itself, including monetary policy" (Barbosa-Filho, 2008, p. 197).

Deduz-se da análise de Barbosa-Filho que, caso a taxa de juros não fosse au-

\footnotetext{
${ }^{5}$ Ao discutir as expectativas de inflação dos participantes da pesquisa Focus, Cristina Freitas recorre ao concurso de beleza keynesiano para afirmar que "os profissionais do mercado financeiro e das consultorias tenderiam a apresentar previsões iguais à média do 'mercado"” (2010, p. 7, nota 12), argumentando que suas remunerações dependem sobretudo da avaliação dos pares. Convém distinguir duas ideias que podem estar misturadas na argumentação de Freitas. O concurso de beleza keynesiano é de fato um exemplo famoso de conformidade de uns com a conformidade (esperada) de outros, em busca de ganhos de coordenação. No entanto, a referência à avaliação dos pares sugere uma preocupação com a reputação. Aqui se encaixa melhor uma outra frase conhecida de Keynes: "Wordly wisdom teaches that it is better for reputation to fail conventionally than to succeed unconventionally" (1936, p. 158). Essas sanções reputacionais revelam (uma convenção que é também) uma norma social informal (Dequech, 2011, p. 487).
} 
mentada, a própria demanda poderia estimular o avanço da produção, de tal forma que as pressões inflacionárias seriam eliminadas, ao menos no longo prazo, e ainda resultariam em crescimento. Para o autor, assim como para outros especialistas na área, o produto potencial é uma variável não observável, estimada a partir do passado e do comportamento esperado da economia. Como expectativas são fortemente influenciadas pelo passado recente (como enfatizava Keynes no que Dequech (2011) chama de "convenção projetiva"), pode-se criar, nas palavras de Barbosa-Filho, uma "self-fulfilling monetary policy" (2008, p. 197). Se um banco central estima que o produto potencial cresce de forma lenta em uma economia e, baseado nessa estimativa pessimista, combate uma aceleração do crescimento por medo de que a inflação ultrapasse a meta, suas próprias ações reduzem o potencial da economia. O investimento é desestimulado e, se o produto potencial for estimado novamente, os dados vão confirmar que o banco central estava certo. Mas isso pode ter acontecido não porque ele calculou corretamente, mas porque sua política colaborou com a produção desse cenário (Barbosa-Filho, 2008, p. 197).

Ainda segundo Barbosa-Filho (2008, p. 196): "if monetary policy is too conservative in setting a low inflation target and a fast speed of convergence to it, the economy may end up locked in a slow-growth equilibrium where the central bank 'kills' any growth acceleration for fears of rising inflation". O autor ressalta que isso não significa que o crescimento sempre vai acontecer caso se acredite nele. Existem limites objetivos, mas a endogeneidade do produto potencial sugere ao autor que pode haver mais de uma posição de equilíbrio. Isso pode corresponder a mais ou menos crescimento.

Embora a análise de Barbosa-Filho (2008) trate da ocorrência de uma profecia autorrealizável sobre o produto potencial, isso por si só ainda não indica a presença de algo convencional. Podemos, no entanto, considerar a possibilidade de adesão de outros agentes ao que seria uma previsão autorrealizável. Agentes privados podem aderir às estimativas (ou ao que imaginam ser as estimativas) do Banco Central sobre o potencial de crescimento não inflacionário da economia. A posição da autoridade monetária seria um ponto de coordenação, assim como em Brière. Isso poderia afetar, por exemplo, as expectativas dos agentes sobre a inflação.

Um processo semelhante de autorrealização de expectativas do Banco Central pode envolver a taxa básica de juros, à qual voltamos porque agora se trata especificamente do nível necessário para compensar o risco país. Se o Banco Central acreditar que é preciso fixar a taxa básica em um patamar elevado, isto contribui para aumentar a despesa do governo com juros e, por essa razão, pode aumentar a percepção de que a situação financeira do governo se deteriorou e de que é maior o risco de não pagamento da dívida pública. Em outras palavras, embora o Banco Central possa argumentar que a taxa básica de juros é alta porque o risco é alto, a partir de certo ponto o risco eleva-se pelo próprio fato de a taxa ser alta (Bresser-Pereira e Nakano, 2002a).

De novo, assim como no caso do produto potencial, a possível autorrealização de uma expectativa do Banco Central sobre a taxa de juros não implica em si mesma uma convenção, mas uma convenção pode surgir quando agentes privados 
aderem a essa expectativa, seja exclusivamente por causa da importância que eles mesmos atribuem ao Banco Central, seja porque acreditam que outros agentes se deixarão influenciar pelo Banco Central.

\section{b) Legitimidade}

Para Dequech (2013), outra razão pela qual os agentes econômicos podem seguir um sistema existente de regras institucionais é sua legitimidade, que pode tornar a instituição mais aceitável para um indivíduo do que uma alternativa desviante (p. 95).

Podemos aplicar essa ideia à adesão ao próprio sistema de metas de inflação. $\mathrm{O}$ fato de diferentes países adotarem esse formato pode contribuir para dar legitimidade ao sistema e justificar antigas e novas adesões. ${ }^{6}$

Parece estar envolvido aí um tipo específico de legitimidade discutido por Dequech, que a chama de legitimidade epistêmica: "a socially recognized appearance of well-foundedness" (2013, p. 96). Isso resulta da associação de um certo padrão de pensamento a valores como a compatibilidade com a evidência empírica, coerência interna, rigor, relevância etc.

O conceito de legitimidade epistêmica pode ser usado para retomar algumas ideias de Brière (2006). $\mathrm{Na}$ análise sobre a coordenação em torno da taxa de juros de mercado, a autora afirma que, no processo autorreferencial que dá origem à representação coletiva, dois tipos de agentes destacam-se: os bancos centrais e os economistas. Ela refere-se a uma percepção generalizada de que as concepções desses agentes estão acima de todas as outras, com bastante legitimidade (2006, p. 186). Brière afirma que, em face da incerteza, as concepções do banco central, em particular, servem de referência e permitem que as expectativas se coordenem (2006, p. 189). ${ }^{7}$ No Brasil, vários agentes privados podem de fato privilegiar as opiniões do Banco Central.

Considerando ainda mais especificamente o caso brasileiro, a adesão de vários indivíduos (incluindo diretores do Banco Central, analistas de bancos e economistas acadêmicos) à crença de que é necessário fixar a taxa básica de juros do Brasil em um patamar elevado ajuda a dar legitimidade epistêmica a essa crença, reproduzindo ou mesmo ampliando as adesões.

Seja com relação à legitimidade do sistema de metas de inflação em geral, seja com relação à legitimidade de seu uso no Brasil em particular, deve-se localizar essa legitimidade no interior de certas comunidades ou grupos, subconjuntos de uma população mais ampla. Como veremos com mais detalhe adiante, o sistema de metas de inflação tem sido objeto de críticas dentro e fora do Brasil. A mesma

\footnotetext{
${ }^{6}$ É o que afirmam Maman e Rosenhek (2009, p. 234) sobre o ocorrido em Israel.

${ }^{7}$ A análise de Brière sobre a complexidade do ambiente em que interagem os participantes do mercado faz lembrar outro argumento de Dequech 2013, p. 94) para seguir uma convenção, a percepção de certos tipos de incerteza (no caso, a incerteza procedimental, resultante do contraste entre a complexidade da situação e as capacidades mentais e computacionais dos agentes).
} 
falta de unanimidade manifesta-se com ainda mais intensidade no caso da alta taxa básica de juros no país. São frequentes as críticas de certos setores do empresariado ou de certos grupos de economistas quanto a isso.

A existência dessa variedade de opiniões torna mais difícil aplicar no caso brasileiro a ideia de uma forma extrema de legitimidade: a naturalidade. Segundo Dequech (2013, p. 99): "the adoption of a certain pattern of behavior or of thought by many people may contribute to making it seem natural, inevitable, self-evident, and the like". Em vez de considerar um padrão institucional mais legítimo que uma alternativa, é possível considerá-lo como a única alternativa. No entanto, as críticas de alguns empresários ou economistas às decisões do Copom quanto à taxa básica são frequentes e públicas o bastante para fazer com que alternativas sejam mais facilmente percebidas como ilegítimas do que como inexistentes.

\section{c) Groupthink}

O psicólogo Irving Janis (1971) discute situações em que grupos responsáveis por decisões equivocadas foram vítimas de "groupthink". Para Janis, uma das características-chave do fenômeno é o desenvolvimento de normas de grupo, que sobrevivem muitas vezes às custas do pensamento crítico. O termo groupthink faz referência ao modo de pensar em que as pessoas se engajam quando a busca da conformidade torna-se tão dominante em um grupo coeso que ela tende a sobrepor a avaliação realista de cursos alternativos de ação (1971, p. 84). Ainda segundo Janis: "When groupthink becomes dominant, there also is considerable suppression of deviant thoughts, but it takes the form of each person's deciding that his misgivings are not relevant and should be set aside, that the benefits of the doubt regarding any lingering uncertainties should be given to the group consensus" (1971, p. $85)$. Isso lembra a ideia do julgamento convencional de Keynes (1937, p. 214).

Dequech $(2013$, p. 96) afirma que o uso da ideia de groupthink para explicar a conformidade pode ser considerado uma combinação de argumentos baseados em sanções (o que nos remete a normas sociais, indo além do puramente convencional) e na legitimidade epistêmica ou no mimetismo motivado por diferenças informacionais. Os dois últimos argumentos implicam conformidade de uns com a conformidade de outros.

O economista comportamental Robert Shiller (1998, p. 25) refere-se a Janis ao tratar da influência dos laços sociais sobre a forma de agir de um grupo. Em artigo mais recente, Shiller considera a possibilidade de ter sido ele próprio vítima de groupthink ao integrar o grupo de aconselhamento econômico do Federal Reserve Bank de Nova York, entre 1990 e 2004. "In my position on the panel, I felt the need to use restraint. While I warned about the bubbles I believed were developing in the stock and housing markets, I did so very gently, and felt vulnerable expressing such quirky views. Deviating too far from consensus leaves one feeling potentially ostracized from the group, with the risk that one may be terminated" (Shiller, 2008). O autor acrescenta: "We all want to associate ourselves with dignified people and dignified ideas".

É possível que algo semelhante ocorra no Brasil, dentro do Copom, o que 
geraria conformidade com conformidade mesmo dentro deste grupo. Mais amplamente, o fenômeno de groupthink pode existir também dentro da academia, entre os defensores da política adotada (assim como entre seus críticos), e entre os analistas dos mercados financeiros.

\section{Arbitrariedade}

A segunda característica que tipifica uma convenção é o fato de ela ser, em algum grau, arbitrária, no sentido de que uma alternativa não claramente inferior ao padrão prevalecente é concebível (Dequech, 2011, p. 482).

Desse ponto de vista, podemos considerar, em primeiro lugar, que o próprio sistema de metas de inflação é em parte arbitrário, já que não é a única opção de política nem necessariamente a melhor. Além disso, vamos argumentar que a forma específica de aplicação do regime no Brasil também tem certa dose de arbitrariedade. Por fim, vamos qualificar a ideia de arbitrariedade, relacionando-a com a possível influência de interesses específicos sobre a definição da taxa básica de juros brasileira.

Apenas para esses fins, sem a pretensão de ser exaustiva, esta seção vai examinar algumas críticas e alternativas ao sistema vigente e à forma como ele tem sido adotado no Brasil.

\section{Arbitrariedade do sistema de metas de inflação}

Há opiniões discordantes sobre a desejabilidade do sistema de metas de inflação.

O ganhador do Prêmio Nobel Joseph Stiglitz tem demonstrado uma visão crítica sobre o regime. Segundo ele, "as metas de inflação são uma dessas ideias simplistas que só são justificadas no contexto de modelos teóricos muito básicos, que agora estão sendo rejeitados” (entrevista a Época Negócios, 2009, p. 159). Stiglitz (2008) afirma que os bancos centrais de todo o mundo formam um grupo fortemente unido e fechado, dado a modismos: eles teriam caído no começo da década de 1980 sob o feitiço do monetarismo; depois que o monetarismo foi desacreditado, a resposta teria vindo na forma de metas de inflação. Stiglitz chama esse novo paradigma de "mantra". Em uma entrevista (ABC Local Radio, 2008), Stiglitz trata o sistema como "religião" e prevê que, em cinco anos, a meta de inflação será vista como mais uma moda, deixada de lado em busca de outra.

Carvalho et al. (2007, p. 146) também afirmam que "o debate e o dissenso sempre acompanharam a evolução da história do pensamento econômico. Não é diferente no que se refere ao aparente novo consenso relacionado à adoção do regime de metas de inflação" (ver também Galbraith, 1999).

Além desses há estudos empíricos que questionam a superioridade do sistema de metas de inflação. Eles argumentam que países que não adotaram o sistema foram igualmente ou mais bem-sucedidos no combate à inflação ou que em vários países a inflação foi domada antes da adoção das metas — para referências e dis- 
cussão, ver Arestis, de Paula e Ferrari (2009), Arestis e Sawyer (2003) e Carvalho et al. (2007, p. 148).

Ao lado da crítica, esses ou outros autores defendem alternativas de política econômica, às vezes sem abandonar por completo o regime de metas de inflação — e.g., Sawyer (2006), Carvalho (2005), Palley (2006), Setterfield (2006) e Vernengo (2008).

\section{Arbitrariedade do regime de metas de inflação brasileiro}

Passando de um nível mais abstrato para um mais concreto de análise, a própria operacionalização do regime de metas no Brasil tem características arbitrárias, no sentido de que há alternativas não claramente inferiores, ao menos na visão de um conjunto não desprezível de autores.

O Brasil usa como principal referência um índice cheio de inflação. Em sua página na internet, o Banco Central justifica sua opção de forma bastante convencional, no sentido da conformidade: "o regime brasileiro considera um índice 'cheio' como referência, em linha com a grande maioria dos países que adotam metas formais para a inflação”. Alguns poucos países utilizam uma medida de núcleo. Outros ainda combinam o uso das duas medidas.

Também quanto ao horizonte temporal para verificar o cumprimento da meta existem alternativas. Alguns países avaliam os resultados mensalmente, considerando a inflação acumulada nos últimos 12 meses. Há outras opções. Por exemplo, a Austrália não fixa o horizonte, mas anuncia que as metas devem ser alcançadas em média ao longo do tempo. O Banco Central do Brasil assume, em sua página na internet, que instituir um horizonte mais longo pode ser uma boa forma de lidar com os choques econômicos com respostas mais suaves de política, mas afirma que em economias como a brasileira, "nas quais ainda está se buscando convergência para melhores padrões internacionais de taxa de inflação, horizontes mais curtos podem ser mais adequados". Para Freitas (2010, p. 4), o horizonte temporal curto pode gerar problemas. Ele facilitaria, por exemplo, a influência de preços administrados no índice de inflação utilizado.

Outra diferença entre países com regimes de metas diz respeito às pesquisas para apuração das expectativas de inflação. Há em outros países alternativas não claramente inferiores à brasileira quanto à consulta a empresas não financeiras e famílias, à periodicidade da pesquisa, ao horizonte das expectativas etc. (Moreno e Villar, 2009; Freitas, 2010).

Oreiro e Passos (2005, p. 157) fazem uma avaliação crítica da estrutura de governança da política monetária no Brasil, argumentando, entre outras coisas, que as expectativas inflacionárias utilizadas no processo de determinação da taxa básica de juros não refletiriam as expectativas dos agentes que têm poder efetivo de formação de preços na economia. Os autores sugerem que o Banco Central leve em conta as expectativas de "vários segmentos da indústria e do comércio" (p. 165).

Oreiro e Passos (2005, pp. 165-166) defendem medidas adicionais, incluindo 
a ampliação do número de membros do Conselho Monetário Nacional — que define a meta de inflação - , de forma a aumentar a sua representatividade.

Mesmo dentro das regras atuais do regime de metas de inflação no Brasil, o patamar escolhido pelo Banco Central para a taxa básica de juros não é sempre visto por todos como inevitável. Mesmo economistas que defendem o regime e participaram de sua gestão na presidência de Armínio Fraga chegaram a criticar o que enxergaram como o excesso de conservadorismo do Copom em momentos posteriores. Além disso, o patamar poderia baixar caso fossem tomadas medidas de política fiscal e creditícia que aumentassem a competitividade das exportações brasileiras sem desvalorizar o Real e permitissem maior ingresso de divisas estrangeiras pela via do saldo comercial.

É importante que o sistema vigente não seja visto, portanto, como uma fórmula única, acima de críticas e possibilidades de revisões.

\section{A arbitrariedade e a influência de interesses específicos}

Um sistema em parte arbitrário, com propriedades também parcialmente arbitrárias, como se pretendeu mostrar acima, daria assim origem a uma taxa básica de juros que é apenas uma opção, não necessariamente a melhor, entre várias possíveis. Dizer que uma convenção é arbitrária não significa, entretanto, que não há diferença entre as alternativas. Embora possa existir uma alternativa que não é inferior do ponto de vista macroeconômico ou do interesse coletivo, as diferentes alternativas podem atender de forma diferente aos interesses de grupos específicos.

Em nota técnica do IPEA, Lima e Brisne (2003) afirmam: “[h]á razões para se acreditar que as previsões de inflação, coletadas pelo Bacen junto a participantes do mercado financeiro, não espelhem as expectativas de mercado em relação à taxa de inflação futura. Se determinado agente econômico percebe que pode afetar a Selic, manipulando o que declara como sendo a sua inflação esperada, então há forte incentivo para que ele não revele o verdadeiro valor esperado para a taxa de inflação" (2003, p. 75). Depois de testes empíricos, Lima e Brisne (2003, p. 83) concluem: "[o]s resultados sugerem que as previsões de mercado, em horizontes mais longos do que três meses, não espelham as verdadeiras expectativas do mercado e que, portanto, não deveriam ter qualquer influência na formulação da política monetária do país". ${ }^{8}$

Para Oreiro e Passos (2005), o fato de a decisão de fixar a taxa de juros no Brasil ser influenciada por expectativas de inflação que refletem as opiniões vigentes entre os analistas do mercado financeiro cria um processo perverso. Nele, o sistema financeiro brasileiro, por intermédio do mecanismo das expectativas inflacionárias, "pode exercer uma forte pressão no sentido de impedir uma queda da

\footnotetext{
${ }^{8}$ Ainda faltam mais estudos empíricos de como são formadas as expectativas dos participantes da pesquisa Focus, inclusive para avaliarmos a ocorrência de conformidade com conformidade e a preocupação com sanções reputacionais.
} 
taxa de juros real abaixo de um patamar considerado 'razoável' para os integrantes desse setor". Outros autores também destacam os interesses do setor financeiro (e.g., Erber, 2011).

Assim, há o risco de que a decisão sobre o nível da taxa básica de juros seja influenciada por interesses específicos.

\section{CONCLUSÃO}

Este artigo é uma tentativa de contribuir para o debate da tese de que a taxa de juros no Brasil é formada por uma convenção, considerando em particular a taxa básica de juros.

Em primeiro lugar, procuramos reforçar as bases conceituais e teóricas da tese da convencionalidade das diferentes taxas de juros. As referências a Keynes e à abordagem convencionalista são certamente pertinentes e ricas, mas não são aplicáveis diretamente à taxa básica de juros, determinada pelo banco central. Keynes tratou de convenções financeiras referentes ao preço de mercado das ações e, sob um conjunto de hipóteses restritivas, à taxa de juros de mercado de longo prazo. Orléan desenvolve uma análise de inspiração parcialmente keynesiana sobre convenções no mercado de ações, enquanto Brière o faz para o mercado de títulos, também sem focar na taxa básica. Além disso, uma defesa rigorosa do argumento da convencionalidade depende da adoção de um conceito suficientemente preciso, a partir do qual se possa mostrar exatamente em que sentido(s) existiria a convencionalidade.

Em segundo lugar, com base em conceito que destaca, entre as propriedades das convenções, a conformidade de uns com a conformidade de outros e a arbitrariedade, tentamos apontar que é possível, de fato, identificar ou, em alguns casos, ao menos sugerir elementos de convencionalidade na determinação da taxa básica de juros no Brasil, durante o regime de metas de inflação. Com relação à conformidade com a conformidade, destacamos como possibilidades relevantes um efeito coordenação, a legitimidade epistêmica de certas ideias ou expectativas e o fenômeno de groupthink, que em parte pode ser sobreposto ao da legitimidade epistêmica. Quanto à arbitrariedade, podem ser apontados argumentos a favor de alternativas não claramente inferiores ao próprio regime de metas de inflação ou à forma como ele tem sido adotado no Brasil, sem negar limites à arbitrariedade, inclusive por causa dos diferentes interesses envolvidos. Ao mesmo tempo, são necessários mais estudos empíricos que ajudem a avaliar melhor os argumentos e as hipóteses por trás da ideia da convencionalidade da taxa básica.

\section{REFERÊNCIAS BIBLIOGRÁFICAS}

ABC LOCAL RADIO (2008). Inflation targeting a 'fad': economist. Austrália, 21 de maio. Disponível em: <http://www.abc.net.au/am/content/2008/s2250953.htm>. 
ARESTIS, P.; DE PAULA, L. F. e FERRARI-FILHO, F. (2009). “A nova política monetária: uma análise do regime de metas de inflação no Brasil”. Economia e Sociedade. 18(1): 1-30.

ARESTIS, P.; SAWYER, M. C. (2003). "Inflation targeting:a critical appraisal”. Levy Economics Institute Working Paper, n.388.

BANCO CENTRAL DO BRASIL. Copom. Série Perguntas mais Frequentes (PMF 03). Diretoria de Política Econômica. Disponível em: <http://www4.bcb.gov.br/?faqeconomia>. Acesso em abril de 2010.

BANCO CENTRAL DO BRASIL. Copom: definição e histórico. Disponível em <http://www.bcb.gov. br/?copomhist $>$. Acesso em setembro de 2010.

BARBOSA-FILHO, N. (2008). "Inflation targeting in Brazil: 1999-2006". International Review of Applied Economics, 22(2): 187-200.

BLINDER, A. S. (1998).Central Banking in Theory and Practice. Cambridge, Mass.: MIT Press.

BRESSER-PEREIRA, L. C. (2003). Desenvolvimento e Crise no Brasil. São Paulo: Editora 34.

BRESSER-PEREIRA, L. C.; NAKANO, Y. (2002a). "Uma estratégia de desenvolvimento com estabilidade". Revista de Economia Política, 22(3): 146-180.

BRESSER-PEREIRA, L. C.; NAKANO, Y. (2002b). "A armadilha dos juros”. Folha de S.Paulo. 10 de fevereiro.

BRIÈRE, M. (2005). Formation des Taux d'Intérêt: anomalies et croyances collectives. Economica. Paris.

CARVALHO, F. J. C. (2005). "Uma contribuição ao debate em torno da eficácia da política monetária e algumas implicações para o caso do Brasil”. Revista de Economia Política, 25(4): 323-336.

CARVALHO, F. J. C. et al. (2007). Economia monetária e financeira: teoria e política. Rio de Janeiro: Elsevier. 2.ed.

CHERNAVSKY, E. (2007). Sobre a construção da política econômica: uma discussão dos determinantes da taxa real de juros no Brasil. Dissertação (Mestrado em Teoria Econômica). São Paulo: Universidade de São Paulo.

CHERNAVSKY, E. (2008). Taxa natural e convenções: uma discussão dos determinantes da taxa real de juros no Brasil. In: XIII Encontro Nacional de Economia Política, João Pessoa.

DEQUECH, D. (2009). "Institutions, social norms, and decision-theoretic norms". Journal of Economic Behavior and Organization, 72(1): 70-78.

DEQUECH, D. (2011). "Financial conventions in Keynes's theory: the stock Exchange”. Journal of Post Keynesian Economics, 33(3): 469-489.

DEQUECH, D. (2013). "Economic institutions: explanations for conformity and room for deviation". Journal of Institutional Economics, 9(1): 81-108.

ÉPOCA NEGÓCIOS (2009). Ninguém acredita em mercados eficientes. Ano 3, n.32, outubro.

ERBER, F. (2011). “As convenções de desenvolvimento no governo Lula: um ensaio de economia política”. Revista de Economia Política, 31(1): 31-55.

ERBER, F. (2012), “The evolution of development conventions”. Revista de Economia Contemporânea, 16(1): $1-22$.

FREITAS, M. C. (2010). "Política monetária e medidas de inflação: a experiência internacional e o Brasil”. Nota técnica Grupo de Conjuntura Fundap. Disponível em <http://debates.fundap.sp. gov.br>.

GALBRAITH, J. K. (1999). "The inflation obsession: flying in the face of the facts". Foreign Affairs, n.78, p. 152-156.

JANIS, I. (1971)." Groupthink”. Psychology Today, 5: 43-46.

KEYNES, J. M. (1936). The general theory of employment interest and money. Londres, Macmillan.

KEYNES, J. M (1937).”The general theory of employment”.The Quarterly Journal of Economics, 51(2): 209-223.

LIMA, E.; BRISNE J. (2003). O Desempenho do Mercado (Focus) e do BACEN na Previsão da Inflação: comparações com Modelos Lineare Univariados. Nota técnica.Boletim de Conjuntura, n.60.

MAMAN, D.; ROSENHEK, Z. (2009)."The contested institutionalization of policy paradigm shifts: the adoption of inflation targeting in Israel”. Socio-Economic Review, 7(2): 217-243. 
MODENESI, A. (2008). “Convenção e rigidez na política monetária: uma estimativa da função de reação do BCB (2000-2007)". Ipea. Texto para discussão, n.1351.

MODENESI, A., MODENESI, L., OREIRO, J., MARTINS, N. (2013), “Convention, Interest Rates and Monetary Policy: a post-Keynesian-French-conventions-school approach". European Journal of Economics and Economic Policies: Intervention, 10(1), no prelo.

MORENO, R.; VILLAR, A. (2009). "Inflation expectations, persistence and monetary policy", BISPaper, 49: 13-51.

OREIRO, J. L.; PASSOS, M. (2005). “A governança da política monetária brasileira: análise e proposta de mudança". Indicadores Econômicos FEE, 33(1): 157-168.

ORLÉAN, A. (1999). Le Pouvoir de la Finance. Paris: Odile Jacob.

PALLEY, T. (2006). "A Post Keynesian framework for monetary policy: why interest rate operating procedures are not enough”. In: GNOS, C.; ROCHON, L.-P. (orgs.) Post-Keynesian Principles of Economic Policy. Cheltenham: Elgar.

SAWYER, M. (2006). "Inflation targeting and the central bank independence: we are all Keynesians now! Or are we?” Journal of Post Keynesian Economics, 28(4): 639-652.

SETTERFIELD, M. (2006). "Is inflation targeting compatible with Post Keynesian economics?" Journal of Post Keynesian Economics, 28(4): 653-671.

SHILLER, R. (1998). "Human behavior and the efficiency of the financial system". NBER Working Papers 6375.

SHILLER, R. (2008). "Challenging the crowd in whispers, not shouts". The New York Times, novembro. Disponível em <http://www.nytimes.com/2008/11/02/business/02view.html?_r=2>. Acesso em outubro de 2010.

STIGLITZ, J. (2008). “The failure of inflation targeting”. Project Syndicate. Disponível em <www. project-syndicate.org/commentary/stiglitz99/English>. Acesso em setembro de 2010.

VERNENGO, M. (2008). "The political economy of monetary institutions in Brazil: the limits of the inflation-targeting strategy, 1999-2005”. Review of Political Economy, 20(1): 95-110. 